\title{
Padrão do Uso de Drogas de Abuso em Usuários de Crack em Tratamento em Uma Comunidade Terapêutica*
}

\author{
Pattern of Illicit Drug Abuse by Crack Users In Treatment In A Therapeutic Community \\ Maycon Rogério Seleghim ${ }^{1}$, Magda Lúcia Félix de Oliveira
}

\section{RESUMO}

A identificação do perfil de usuários de drogas de abuso é uma das primeiras açôes para a elaboração de políticas públicas. Objetivo. $\mathrm{O}$ objetivo do estudo é descrever o padrão do uso das principais drogas de abuso em usuários de crack em tratamento em uma Comunidade Terapêutica. Método. Pesquisa descritiva, com delineamento de série de casos, realizada com 20 usuários de crack acessados em uma Comunidade da regiáo Sul do Brasil, utilizando entrevista semiestruturada. Os dados foram analisados por meio de estatística descritiva simples. Resultados. A maioria dos usuários tinha idade entre 20 e 39 anos, não possuía relacionamento conjugal, tinha em média 7,4 anos de estudo, e estavam desempregados. O padrão do uso de drogas caracterizou-se pelo uso múltiplo, com início de drogas lícitas e ilícitas na juventude. A trajetória confirmou uma escalada no uso das substâncias psicoativas, iniciando com o tabaco e/ou álcool e finalizando com o uso de crack. Conclusóes. Conclui-se que o perfil dos casos investigados foi semelhante ao descrito na literatura, mas a presença do padrão de uso múltiplo e de uma progressão no consumo de drogas remete à necessidade de políticas públicas voltadas a interrupção dessas características.

Unitermos. Transtornos Relacionados ao Uso de Substâncias, Drogas Ilícitas, Cocaína Crack, Comunidade Terapêutica.

Citaçáo. Seleghim MR, Oliveira MLF. Padrão do Uso de Drogas de Abuso em Usuários de Crack em Tratamento em Uma Comunidade Terapêutica.

\begin{abstract}
The identification of illicit drug users' profile is one of the first activities in the elaboration of public policies. Objective. Current investigation described the usage pattern of the main illicit drugs by crack users treated in a Therapeutic Community (TC). Method. A descriptive survey, with a series of cases, featuring semi-structured interview, was conducted with 20 crack users treated in a TC in a south region of Brazil. Data were analyzed by simple descriptive statistics. Results. Most users were within the 20 - 39 year-old bracket, were unmarried, had on average 7.4 years of schooling, and were unemployed. The pattern of drug use is characterized by frequent use, with an onset of licit and illicit drugs in their youth. Their life trajectory confirmed an escalation of the use of psychoactive substances, starting with tobacco and / or alcohol and ending with crack. Conclusions. The profile of the cases investigated was similar to that described in the literature, but the presence of polydrug use and a progression in drug use refers to need for public policies to interrupt these characteristics.
\end{abstract}

Keywords. Substance-Related Disorders, Street Drugs, Crack Cocaine, Therapeutic Community.

Citation. Seleghim MR, Oliveira MLF. Pattern of Illicit Drug Abuse by Crack Users In Treatment In A Therapeutic Community.

\footnotetext{
*Artigo extraído da Dissertaçáo de Mestrado intitulada "Recursos e adversidades no ambiente familiar de usuários de crack", realizada com apoio financeiro do CNPq e Ministério da Saúde, Edital no 41/2010.

Trabalho realizado na Universidade Estadual de Maringá (UEM), Maringá-PR, Brasil.

1.Enfermeiro do Hospital Paraná e do Hospital Universitário Regional de Maringá, Mestre em Enfermagem, Doutorando do Programa de Pós-Graduação em Enfermagem Psiquiátrica da Escola de Enfermagem de Ribeirão Preto, Universidade de São Paulo, Ribeirão Preto-SP, Brasil.

2.Enfermeira, Doutora em Saúde Coletiva, Coordenadora do Centro de Controle de Intoxicaçóes do Hospital Universitário de Maringá, Maringá-PR, Brasil.
}

Endereço para correspondência: Rua Osvaldo Cruz, 340, ap. 309, Zona 07 Tel: (44) 8801-9447 CEP: 87020-200, Maringá-PR, Brasil. E-mail: mseleghim@yahoo.com.br 


\section{INTRODUÇÃO}

O uso de drogas é um fenômeno complexo por acarretar prejuízo ao sujeito, à família e à sociedade, na forma de repetência escolar, perda de emprego, rupturas familiares, violências e encarceramentos ${ }^{1}$. As drogas podem ser lícitas, como o álcool e o tabaco, ou ilícitas, como a maconha, a cocaína e o crack.

Geralmente, usuários de drogas estão escondidos da sociedade, por usar uma droga ilegal e pela criminalização social relacionada ao uso, ou pela dificuldade em assumir o "vício" de uma droga legal, o que ocasiona dificuldades em caracterizar este grupo populacional, bem como estabelecer o padrão de uso das substâncias psicoativas $^{2}$.

Os usuários podem ser encontrados em delegacias de polícia e nos presídios, onde se encontram pelos crimes relacionados às drogas; em hospitais, em consequência de violência, ou para cuidados de saúde pelas drogas ou outras condições a elas relacionadas; e em serviços especializados para tratamento da dependência química, onde são internados para recuperação ou por "overdose"

Estudo realizado com usuários de crack, atendidos em uma unidade de emergência psiquiátrica, encontrou que, além da perda dos vínculos relacionais com a família e com o meio social, presença de drogas e violência no ambiente familiar, a procura pelo atendimento surgiu como um meio de "aliviar" os longos períodos de uso da droga na rua, sem uma motivação real para cessar ou alterar o padrão de uso das substâncias psicoativas (SPA) ${ }^{3}$.

Pesquisa desenvolvida com coorte de 131 usuários de crack com histórico de tratamento, encontrou que a recorrência e a persistência do consumo nos anos pós-alta de tratamento refletem novos padrôes de uso do crack, indicando que investigaçóes futuras deveriam se voltar para a elucidação de momentos do curso de vida dos indivíduos em que outros dispositivos (de saúde, sociais e culturais) que não os tratamentos formais, compareçam como apoiadores na alteração do padrão de uso das SPÁ .

As drogas de abuso são definidas como substâncias consumidas por qualquer forma de administração, que altera o humor, o nível de percepção ou o funcionamento do sistema nervoso central. Nesse contexto, o cracké um subproduto da cocaína, substância encontrada nos países da América do Sul e da América Central, que surgiu no
Brasil no final da década de 1980 . Seu uso é considerado um problema de saúde pública emergente, pela ocorrência de violências, ao seu impacto no financiamento do sistema de saúde, além dos prejuízos individuais e familiares $^{5,6}$.

Identificar o padrão de uso das SPA pode ser útil para classificar os usuários para constituição de grupos homogêneos quanto aos tipos de drogas, estabelecer o nível de consumo de cada uma das drogas, identificar as razões de uso e a gravidade do quadro da dependência, que permitirão avaliar a eficácia dos esquemas terapêuticos e os resultados da terapêutica pela mudança no padrão de consumo ${ }^{7}$.

Também, a identificação do perfil e do padrão de consumo das drogas são aspectos relevantes na avaliação inicial do uso das drogas, sendo considerada uma das primeiras ações para a elaboração de políticas públicas ${ }^{8}$.

Destarte, verificam-se poucos estudos destinados à caracterização do padrão de uso de drogas em indivíduos internados em serviços especializados para tratamento da dependência química, incluindo as Comunidades Terapêuticas (CT). Esse ambiente de tratamento surgiu na Grã-Bretanha na década de 1940, sendo inicialmente utilizado para a atençấo à saúde de pacientes psiquiátricos, e é uma modalidade de serviços de atenção a pessoas com problemas decorrentes do uso ou abuso de substâncias psicoativas, que devem funcionar segundo modelo psicossocial $^{9,10}$.

Diante do exposto, o objetivo do presente estudo foi descrever o padrão do uso das principais drogas de abuso em usuários de crack em tratamento em uma CT da região sul do Brasil.

\section{MÉTODO}

Trata-se de uma pesquisa descritiva, com delineamento de uma série de casos, realizada em uma CT da regiâa Sul do Brasil. O estudo de série de casos consiste na descrição de um grupo de dez ou mais indivíduos, com uma doença ou problema em particular, ricos em informação a respeito do objeto pesquisado ${ }^{3}$.

A CT em questão é uma entidade não-governamental, com capacidade para 60 residentes, assistindo usuários de drogas do sexo masculino a partir dos 12 anos de idade, em regime de residência ( 9 meses); a entidade 
segue os critérios de funcionamento da Agência Nacional de Vigilância Sanitária (Anvisa), é registrada na Federação Brasileira de Comunidades Terapêuticas, e no Conselho Municipal de Políticas sobre Drogas do município de abrangência.

\section{Populaçáo}

A população em estudo foi constituída por amostra intencional por critérios, incluindo 20 indivíduos do sexo masculino, com idade igual ou superior a 18 anos, classificados funcionalmente como habituais ou dependentes de crack, e em tratamento na Comunidade no mês de maio de 2011.

Considerando os diversos sistemas de classificação do padrão de uso das substâncias psicoativas, adotou-se no presente estudo a definição de padrão de uso como o conjunto de variáveis que fornecem dados sobre o início e a continuidade do consumo de uma substância psicoativa $^{11}$.

A funcionalidade refere-se ao grau de ruptura que o indivíduo apresenta em sua vida social em decorrência do uso de drogas. Adotou-se a classificação proposta pela Organização das Nações Unidas para a Educação, Ciência e Cultura (Unesco) ${ }^{12}$ :

- usuário experimental: limita-se a experimentar uma ou várias drogas, como curiosidade, desejo de novas experiências, pressão de grupo;

- usuário ocasional: utiliza uma ou várias substâncias de vez em quando, se o ambiente for favorável e a droga disponível;

- usuário habitual: faz uso frequente de drogas e em suas relaçóes já se observam sinais de ruptura. Mesmo assim, ainda "funciona" socialmente, embora com riscos de dependência;

- usuário dependente: vive pela droga e para a droga, quase que exclusivamente. Como consequência, rompe os seus vínculos sociais, o que provoca isolamento e marginalização.

\section{Procedimento}

Para seleção dos sujeitos recorreu-se à consulta ao Relatório de Etapas, um impresso próprio da Comunidade que identifica os usuários de acordo com a etapa do tratamento, compilando os itens droga de uso, fun- cionalidade, e idade. A CT contava com um total de 34 residentes no primeiro dia da coleta dos dados, no entanto, foram identificados 20 usuários de crack habituais ou dependentes.

Os usuários foram abordados individualmente pelo pesquisador e um supervisor e/ou profissional de saúde para participar do estudo. Após essa aproximação inicial, os usuários eram encaminhados a uma sala reservada para o esclarecimento dos motivos e dos aspectos éticos referentes à pesquisa, onde após a assinatura do Termo de Consentimento Livre e Esclarecido em duas vias, se procedia à realização da entrevista.

Para coleta dos dados, utilizou-se entrevista semiestruturada, orientada por um roteiro constituído por dados socioeconômicos e sobre o padrão do uso de drogas de abuso. Foram utilizados no presente estudo: 1) dados socioeconômicos: faixa etária, raça/cor, anos de estudo, relacionamento conjugal, filhos, religião e situação ocupacional; 2) dados sobre o padrão do uso das principais drogas de abuso (tabaco, álcool, maconha, cocaína e cra$c k$ ): idade de início - criança (até 10 anos), jovem (10 a 24 anos), e adulto ( 25 a 60 anos) ${ }^{13}$; funcionalidade - experimental, ocasional, habitual e dependente; tempo de uso - 5-9, 10-19, 20-29, e $\geq 30$ anos; e trajetória do uso - da primeira a quinta droga utilizada.

No caso do padrão do uso de crack, também foram estabelecidos aspectos comportamentais específicos, como o instrumento de uso - latas de alumínio, cachimbos de metais, e outros; a socializaçấo do uso - isolado, grupal, ou aos pares; e marcadores de gravidade - atividades criminosas, e a venda de pertence próprio ou familiar para aquisição da droga.

A sequência do uso das drogas de abuso foi realizada pelos próprios usuários, sendo oportunizada a inclusão de outras drogas além das pesquisadas. $\mathrm{O}$ início concomitante de mais de uma droga foi considerado desde que o uso tivesse ocorrido no mesmo ano.

\section{Análise dos Dados}

Os dados obtidos a partir dos casos investigados foram tabulados no software Microsoft Excel e analisados por meio de estatística descritiva simples (medidas de localização central e de dispersão) no programa computacional Bioestat ${ }^{\circledR}$ 5.0. Os resultados estâo apresentados em 
forma de tabelas e quadros, e discutidos frente à literatura científica pertinente.

A realização do estudo foi autorizada pela Comunidade Terapêutica e aprovada pelo Comitê Permanente de Ética em Pesquisas com Seres Humanos da Universidade Estadual de Maringá (Parecer no 301/11). Para garantia do anonimato, os usuários foram identificados com a letra $U$, seguida de algarismos arábicos, conforme a sequência de realização das entrevistas.

\section{RESULTADOS}

Os dados de caracterização socioeconômica dos 20 usuários de crack investigados podem ser observados na Tabela 1 . Verificou-se que a idade variou de 18 a 44 anos, com uma média de 28,9 anos (mediana de 29,0 anos, moda de 28,0 e desvio padrão de 6,8), no entanto, a maioria tinha idade entre 20 e 39 anos (16 casos).

O número médio de anos de estudo foi de 7,4, com variação de dois a 11 anos estudados (mediana de 8,0 anos, moda de 11,0 e desvio padrão de 2,7 ). No que se refere à raça/cor, a maioria dos usuários se autoclassificaram pardos (6 casos) e negros (5 casos), e nove se declararam brancos. A grande maioria (16 casos) deles não possuía relacionamento conjugal durante a realização das entrevistas, no entanto 11 afirmaram possuir filhos, sendo que o número médio de filhos por indivíduo foi de um (mínimo de 0 e máximo de 4 filhos).

Quase a totalidade relatou possuir religiâo, sendo que 17 eram católicos, mas dois afirmaram não ser adeptos de nenhuma religiâo sem, contudo, se considerarem ateus. Apesar da situação ocupacional indefinida pela institucionalização na CT, 13 usuários afirmaram estar desempregados, e sete relataram algum tipo de vínculo empregatício formal ou estarem empregados.

\section{O padrão de uso das principais drogas de abuso}

Evidenciou-se entre os usuários de crack o uso múltiplo de drogas ou poliuso, em oposição ao uso exclusivo de crack, visto que 16 indivíduos também relataram o uso de tabaco, 19 o uso de álcool, 18 o uso de maconha, e oito relataram ser usuários de cocaína. (Tabela 2).

De um modo geral, a idade de início do uso de drogas lícitas (tabaco e álcool) e ilícitas (maconha, cocaína e $c r a c k$ ) foi predominante na juventude. Em relação
Tabela 1

Características socioeconômicas dos usuários de crack $(n=20)$

\begin{tabular}{|c|c|c|}
\hline Variáveis & Descritores & $\mathbf{n}$ \\
\hline \multicolumn{3}{|c|}{ Faixa etária (anos) } \\
\hline & $18-19$ & 02 \\
\hline & $20-29$ & 08 \\
\hline & $30-39$ & 08 \\
\hline & $40-44$ & 02 \\
\hline \multicolumn{3}{|c|}{ Anos de estudo } \\
\hline & $1-4$ & 03 \\
\hline & $5-8$ & 10 \\
\hline & $9-11$ & 07 \\
\hline \multicolumn{3}{|l|}{ Raça/cor } \\
\hline & Branca & 09 \\
\hline & Parda & 06 \\
\hline & Negra & 05 \\
\hline \multicolumn{3}{|c|}{ Relacionamento conjugal } \\
\hline & Sim & 05 \\
\hline & Não & 16 \\
\hline \multicolumn{3}{|l|}{ Religiáo } \\
\hline & Católico & 17 \\
\hline & Não possui & 02 \\
\hline & Testemunha de Jeová & 01 \\
\hline \multicolumn{3}{|c|}{ Situaçáo ocupacional } \\
\hline & Desempregado & 13 \\
\hline & Empregado & 07 \\
\hline
\end{tabular}

ao uso de tabaco e de álcool, a maioria dos entrevistados apontou o início na juventude (13 e 18 casos respectivamente), porém, três usuários relataram o uso de tabaco e um o uso de álcool ainda na infância.

A idade média do início do uso de tabaco foi de 14,4 anos (mediana de 14,1, moda de 14,0 e desvio padrão de 2,1 ), sendo que o uso habitual (12 casos) por um período entre seis a 19 anos (11 casos) foram os de maior ocorrência. Por outro lado, a idade média do início do uso de álcool foi de 13,7 anos (mediana de 13,2, moda 13,0 e desvio padrão de 1,6), com maior gravidade de uso, visto que metade dos usuários fazia o uso dependente por um período superior a dez anos.

No que se refere às drogas ilícitas, o uso de maconha também foi predominante na juventude (18 casos), com uma idade média de início de 14,2 anos (mediana de 14,1 , moda de 14,0 e desvio padrão de 2,2). Observou-se forte aceitaçấo e agregação do consumo de maconha entre os entrevistados, pois a maioria fazia uso habitual por um período superior a dez anos (14 casos). 
Tabela 2

Padrão do uso das principais drogas de abuso lícitas e ilícitas $(n=20)$

\begin{tabular}{|c|c|c|c|c|c|}
\hline \multirow[b]{2}{*}{ Variáveis } & \multicolumn{2}{|c|}{ Drogas lícitas } & \multicolumn{3}{|c|}{ Drogas ilícitas } \\
\hline & $\begin{array}{l}\text { Tabaco } \\
(\mathrm{n}=16)\end{array}$ & $\begin{array}{l}\text { Álcool } \\
(\mathrm{n}=19)\end{array}$ & $\begin{array}{c}\text { Maconha } \\
(\mathrm{n}=18)\end{array}$ & $\begin{array}{c}\text { Cocaína } \\
(\mathrm{n}=08)\end{array}$ & $\begin{array}{l}\text { Crack } \\
(\mathrm{n}=20)\end{array}$ \\
\hline \multicolumn{6}{|l|}{ Idade de início } \\
\hline Criança & 03 & 01 & - & - & - \\
\hline Jovem & 13 & 18 & 18 & 07 & 14 \\
\hline Adulto & - & - & - & 01 & 06 \\
\hline \multicolumn{6}{|l|}{ Funcionalidade } \\
\hline Experimental & 04 & 01 & 01 & 12 & - \\
\hline Ocasional & 04 & 03 & 03 & 06 & - \\
\hline Habitual & 12 & 06 & 15 & 02 & 07 \\
\hline Dependente & - & 10 & 01 & - & 13 \\
\hline \multicolumn{6}{|c|}{ Tempo de uso (anos) } \\
\hline$\leq 5$ & 02 & 01 & 01 & 02 & - \\
\hline $6-9$ & 05 & 04 & 04 & 01 & 14 \\
\hline $10-19$ & 06 & 11 & 11 & 04 & 05 \\
\hline $20-29$ & 01 & 02 & 02 & 01 & 01 \\
\hline$\geq 30$ & 02 & 01 & 01 & - & - \\
\hline
\end{tabular}

A idade média de início do uso de cocaína foi a maior entre as drogas investigadas - 17,1 anos, com a ocorrência de um caso iniciando na fase adulta do ciclo vital (mediana de 16,9, moda de 21,0 e desvio padrão de $2,4)$. Nenhum usuário fazia o uso dependente de cocaína na forma aspirada ou endovenosa, sendo que a maioria relatou o uso experimental (12 casos) ou ocasional (6 casos). Entre aqueles que relataram o uso ocasional e habitual, o tempo de uso foi superior a seis anos (8 casos).

O padrão do uso de crack apresentou-se diferente das demais drogas investigadas, visto que a idade média de início foi de 15 anos (mediana de 14,9, moda de 16,0 e desvio padrão de 1,2), e apesar de ocorrer de forma predominante na juventude (14 casos), seis usuários relataram o início do uso na fase adulta do ciclo vital. A grande maioria também fazia o uso dependente de crack por um período entre seis a noves anos (13 casos).

Após a consolidação das informaçóes referentes às principais drogas de abuso, foi identificada a trajetória do uso de drogas, que pode ser observada no Quadro 1.

Verificou-se que as primeiras drogas utilizadas pelos usuários de crack foram o tabaco e/ou álcool, e em cinco casos estas drogas estavam associadas a solventes e/ou maconha. A segunda droga mais consumida foi a maconha (15 casos), iniciada concomitantemente com a cola de "sapateiro" em sete usuários. Chama atenção que dois usuários iniciaram uso do crack já neste período.

A terceira droga mais utilizada pelos usuários foi a cocaína (13 casos), e em cinco casos o uso de crack foi iniciado neste período. Como quarta ou quinta droga utilizada pelos entrevistados, o crack foi o de maior ocorrência (10 e 2 casos, respectivamente). No geral, o crack foi a última droga de uso em metade dos casos investigados.

Quanto aos aspectos comportamentais relacionados ao padráo do uso de crack, as latas de alumínio como instrumento de uso foi apontado por quase todos os entrevistados (19 casos). No entanto, quatro usuários também relataram o consumo da droga em cachimbo de metal improvisado, e quatro faziam o uso de crack associado com tabaco ou maconha, denominado por eles de "pitilho" ou "mesclado" (Tabela 3).

No que se refere à socializaçáo do uso de crack, o uso isolado (11 casos), caracterizado pelos entrevistados com uma estratégia para lidar com o possível risco de lesôes decorrentes de brigas e desentendimentos entre os membros do grupo, foi o mais citado, mas foi indicado 
Quadro 1

Trajetória do uso de drogas de abuso pelos usuários de crack. $(n=20)$

\begin{tabular}{|c|c|c|c|c|c|}
\hline Usuário & Primeira & Segunda & Terceira & Quarta & Quinta \\
\hline U1 & Tabaco/Álcool & Maconha & Cocaína & Crack & \\
\hline U2 & Tabaco/Álcool & Maconha & Cocaína & Crack & - \\
\hline U3 & Tabaco/Álcool & Maconha & Cocaína & Crack & Heroína \\
\hline U4 & Tabaco/Álcool & Maconha/Cola & Cocaína/Crack & Tinner & - \\
\hline U5 & Álcool & Maconha & Cocaína & Crack & - \\
\hline U6 & $\begin{array}{l}\text { Tabaco/Álcool/ } \\
\text { Tinner/ } \\
\text { Éter/Benzeno }\end{array}$ & Maconha/Cola & Cocaína/Crack & - & - \\
\hline U7 & Álcool & Tabaco/Maconha & Cola & Cocaína & Crack \\
\hline U8 & Álcool & Maconha & Cocaína & Estasy & Crack \\
\hline U9 & Tabaco/Álcool & Maconha/Cola & Cocaína & Crack & - \\
\hline U10 & Álcool & Maconha & Cocaína & Crack & - \\
\hline U11 & Tabaco & $\begin{array}{l}\text { Álcool/Cola/Ma- } \\
\text { conha }\end{array}$ & Crack & Cocaína & - \\
\hline U12 & Tabaco & Maconha/Cola & Álcool & Crack & Cocaína \\
\hline U13 & Tabaco/Álcool & Maconha & Crack & - & - \\
\hline U14 & Tabaco/Álcool & Maconha/Cola & Cocaína & Crack & \\
\hline U15 & $\begin{array}{l}\text { Tabaco/Álcool/ } \\
\text { Maconha }\end{array}$ & Crack & Cocaína & - & - \\
\hline U16 & $\begin{array}{l}\text { Tabaco/Álcool/ } \\
\text { Tinner/ } \\
\text { Maconha/Cola }\end{array}$ & Cocaína & Crack & - & - \\
\hline U17 & Álcool & Maconha/Cola & Tabaco/Cocaína & Crack & LSD \\
\hline U18 & Tabaco/Maconha & Crack & - & - & - \\
\hline U19 & Tabaco/Álcool/Cola & Maconha & Cocaína & Crack & - \\
\hline U20 & Tabaco/Álcool & Maconha & Cocaína & Crack & - \\
\hline
\end{tabular}

por sete destes o uso em grupo (7 casos), como uma forma de proteção dos efeitos audiovisuais da droga.

Os marcadores da gravidade do uso de crack apontaram que a maioria dos usuários já havia praticado alguma atividade criminosa, como a venda de drogas, roubos e assaltos, ou vendido algum pertence próprio ou da família para adquirir o crack.

\section{DISCUSSÃO}

O perfil socioeconômico encontrado no estudo foi semelhante ao descrito na literatura sobre usuários de drogas no Brasil, apesar da carência de estudos com usuários de crack em tratamento: jovens ou adultos no início do ciclo vital, em fase economicamente ativa e reprodutiva, sem vínculo empregatício, baixo poder aquisitivo; e nível de escolaridade incompatível para idade, conformando o ciclo vicioso da repetência e da evasão escolar ${ }^{11,14}$.

No entanto, chama atençáo no grupo estudado a presença de usuários da raça/cor parda e negra em uma região onde a maioria da populaçấo se declara branca. Em termos regionais, a composição por raça/cor é bastante diferenciada, refletindo a origem das várias correntes migratórias que se distribuíram de formas diversas no território nacional ${ }^{15}$.

A idade dos usuários de crack tem sido foco de investigação pelas altas taxas de mortalidade ou pela longevidade de consumo, o que poderia indicar uma adaptação do usuário à cultura da droga. Estudo realizado com coorte de 131 usuários de crack admitidos em uma enfermaria de desintoxicação em São Paulo, SP, entre 1992 e 1994, 
Tabela 3

Características comportamentais do padrão do uso de crack e gravidade $(n=20)$

\begin{tabular}{ll}
\hline Variáveis & $\mathbf{n}$ \\
\hline - Características comportamentais & \\
Instrumento de uso & 19 \\
Lata de alumínio & 04 \\
Cachimbo de metal & 04 \\
Associado com maconha e/ou cigarro & \\
Socializaçáo do uso & 11 \\
Isolado & 07 \\
Grupo & 02 \\
Pares & \\
- Marcadores de gravidade & 13 \\
Atividade criminosa & 07 \\
Sim & \\
Não & 19 \\
Venda de pertences próprios elou familiares & 01 \\
Sim & \\
Náo & \\
\hline
\end{tabular}

localizou 107 indivíduos ao final de 12 anos de acompanhamento, e 27 mortes foram confirmadas, sendo a maioria por homicídio ${ }^{4}$.

Estudo sobre as estratégias desenvolvidas por usuários para lidar com os riscos decorrentes do consumo da droga indica que as mudanças na cultura do crack podem contribuir para aumentar a expectativa de vida dos consumidores, visto que é corrente encontrar usuários com mais de cinco anos de consumo ${ }^{6}$.

O predomínio de usuários com idades entre 20 e 39 anos, aponta desfiliação social na fase produtiva da vida, com perda de vínculos econômicos e afetivos, indicado nesse estudo pela informação de desemprego e pela situação de solteiros, que pelo uso da droga ainda não constituíram famílias ${ }^{15}$.

O nível de escolaridade incompatível para idade evidenciado entre os usuários de crack, podendo implicar em menor inserção no mercado de trabalho formal, medido no estudo pela grande ocorrência de usuários desempregados, menor disponibilidade financeira e, consequentemente, maior vulnerabilidade ao uso de dro$\operatorname{gas}^{6,11,15}$.

Em relação ao padrão do uso das drogas de abuso, chamou atenção a existência do uso múltiplo de drogas ou poliuso. $\mathrm{Na}$ literatura internacional, o uso múltiplo de drogas foi dividido em concurrent polydrug use (CPU) e simultaneous polydrug use (SPU), diferenciados entre si pelo contexto temporal de uso. Enquanto o CPU faz referência ao uso de mais de uma substância em ocasióes diferentes, o SPU envolve o emprego de duas ou mais drogas em uma mesma sessão de consumo (uso múltiplo do tipo simultâneo) ${ }^{16}$.

O uso múltiplo pode dificultar a identificação apropriada dos transtornos de uso de substâncias existentes, servindo como um fator de confusão sobre a interferência de uma dada substância sobre a saúde, além de dificultar a adesão e o sucesso de uma possível abordagem ${ }^{17}$.

Em geral, os usuários iniciaram o uso de drogas na adolescência/juventude, fase de extrema curiosidade e da valorização do grupo de amigos, e, apesar da iniciação ocorrer muitas vezes de maneira experimental nesta faixa etária, verificam-se comportamentos que continuaram na vida adulta ${ }^{1}$.

Ao identificar a trajetória do uso de drogas, segundo a memória de abstinentes do crack, realiza-se, indiretamente, um processo semelhante ao do acompanhamento de uma coorte. No presente estudo, verificaram-se três trajetórias distintas de consumo e fatores associados: tabaco/álcool como drogas de iniciação; maconha como primeira droga ilícita; e cocaína/crack como a droga utilizada antes do início do tratamento.

O uso de outras substâncias além do crack é presente entre os usuários, com relatos de utilização de diferentes substâncias, tanto no curso de vida quanto no último ano e o estabelecimento da trajetória por meio da memória dos usuários do presente estudo ratificaram essa tendência, porém sem estabelecer com clareza como as associaçóes se processaram e os significados delas ${ }^{4}$.

Apesar de os usuários de crack iniciarem o uso de tabaco em média aos 14,4 anos de idade, a maioria fazia o uso habitual, de forma recorrente, por um período entre seis a 19 anos. A dependência física e psicológica causada pelo uso de tabaco pode levar ao uso frequente e persistente por um longo período, como observado no estudo $^{18}$.

Observou-se que o padrão do uso de álcool entre os usuários de crack foi semelhante ao do tabaco, pois 
ocorreu predominantemente na juventude, com um uso dependente por um período superior a dez anos. Isso remete ao fato de que o início do álcool, geralmente está associado ou próximo ao uso do tabaco, porém o uso de álcool apresenta maior gravidade, indicado no estudo pela ocorrência de uso dependente ${ }^{18}$.

Medidas legais adotadas por governos são importantes para impedir o acesso dos adolescentes às drogas. No Brasil, a venda do álcool e do tabaco é proibida para jovens até 18 anos por meio da Lei no 8.069/9. Porém, a legislação nem sempre é comprida, o que predispóe a aquisição de drogas consideradas lícitas a menores de 18 $\operatorname{anos}^{19}$.

Estudo realizado com dados de um centro de assistência toxicológica do Paraná nos anos de 2003 a 2007, sobre o uso de álcool por crianças e adolescentes do sexo masculino, aponta que as crianças e os adolescentes do sexo masculino têm 3,4 vezes mais chance de intoxicação alcoólica, comparados com os do sexo feminino ${ }^{20}$. Assim, medidas de enfrentamento que considerem o sexo como fator de risco para o início do uso de álcool devem ser levadas em consideração, no intuito de deter a exposição aumentada ao uso de drogas.

Quanto ao padrão do uso de maconha, a maioria fazia uso habitual por um período superior a dez anos. Estudo que objetivou avaliar a relação entre o consumo precoce de tabaco e álcool e o risco de consumir maconha encontrou associação significativa com o início precoce e a frequência aumentada do consumo de tabaco, e com o consumo simultâneo de álcool, apontando que as estratégias de prevenção devem ser orientadas para evitar o consumo precoce dessas substâncias na adolescência ${ }^{21}$.

$\mathrm{O}$ uso associado com maconha surgiu como a possibilidade de reduzir os efeitos negativos do crack. Autores apontam a adoção da maconha como importante estratégia à redução dos danos associados ao uso de crack, diminuindo a fissura e os demais sintomas da síndrome de abstinência, o que possibilitaria, em longo prazo, a reintegração sócio-laboral do usuário ${ }^{22}$.

O início do uso de cocaína também foi predominante na juventude, sendo que a maioria já havia experimentado ou usava ocasionalmente. Essa situação diferiu da literatura, em que, em uma coorte de usuários de crack, a transição da primeira via de utilização da cocaína (for- ma aspirada), mais comumente utilizada como via inicial, para a segunda (forma inalada) não implicou necessariamente no abandono daquela ${ }^{4}$.

De acordo com os entrevistados do presente estudo, a cocaína em sua forma aspirada era utilizada somente em situaçōes de festas e geralmente associada ao álcool. Nesse sentido, autores apontam que a combinação entre cocaína e álcool tende a reforçar os efeitos positivos da cocaína, sendo ambas as substâncias administradas em maior quantidade ${ }^{4,23}$.

Apesar dos usuários em estudo consumirem o crack de maneira habitual ou dependente, de maior gravidade, outros tipos de funcionalidade devem ser investigados, como o uso ocasional, principalmente quanto às estratégias adotadas para seu alcance, visto que os usuários que fazem este tipo de consumo apresentam menos rupturas com sua rede de relaçóes social, de trabalho e familiar ${ }^{11,24}$.

A importância da identificação da sequência do uso de drogas é justificada por ser uma ferramenta eficaz na construção de estratégias para deter a exposição, cada vez maior, ao risco proporcionado por uma progressão de drogas ${ }^{8}$. A maioria dos entrevistados iniciou o uso de drogas com o álcool e/ou tabaco, de ampla disponibilidade comercial entre os jovens, ainda que a venda seja proibida por lei, e figura como elemento de grande aceitação cultural, difundido em todas as classes socioeconômicas ${ }^{20,25}$. A precocidade de início do uso de álcool é um dos fatores preditores mais relevantes de problemas futuros, aumentando significativamente o risco para beber pesado na idade adulta, em ambos os sexos ${ }^{26}$.

O uso do crack, como última droga, é relatado na literatura. Estudo com usuários de crack acessados pela estratégia bola de neve na cidade de São Paulo, cujo objetivo é identificar uma progressão no uso de drogas, encontrou que o crack foi a última droga de uso em 31 entrevistados, e concluiu que os usuários de drogas avançam em uma busca de emoções até se depararem o crack, impossibilitando a troca ou a volta pela dependência e/ou compulsão que se instala ${ }^{8}$.

O uso de latas de alumínio pelos usuários de crack ocorre em função do menor custo e da dificuldade de portabilidade dos cachimbos de metais. A identificação do consumo em latas de alumínio merece atenção devido aos danos que esta forma de uso pode acarretar, que além 
do risco continuado de queimaduras labiais, elevados níveis sérico de alumínio pode trazer mais danos ao sistema nervoso central ${ }^{27}$.

O uso isolado do crack é uma estratégia adotada pelos usuários para lidar com o possível risco de lesóes, decorrentes dos desentendimentos entre os membros do grupo, provocados pela fissura e paranoia, e também pelo medo da violência em geral ${ }^{6}$.

Em relação aos marcadores de gravidade, a venda de pertences próprios e/ou familiares, e a realização de atividades criminosas, também são comuns entre os usuários, entre outros fatores, pela sensação de urgência pela droga, podendo levar o usuário a praticar atividades ilícitas, ou a troca de sexo por dinheiro ${ }^{6,11}$.

\section{CONCLUSÕES}

Considerando que a cultura do crack apresenta características contextuais especificas, a escolha por uma CT que atende exclusivamente usuários de drogas do sexo masculino foi pautada na maior ocorrência deste sexo na cultura do crack. Também, estudos desenvolvidos em serviços especializados para tratamento da dependência química permitem maior proximidade para o estabelecimento de vínculo, dando maior fidedignidade aos dados obtidos.

O uso múltiplo de drogas, em oposição ao uso exclusivo de crack, foi evidenciado na série de casos estudada. No geral, a idade de início do uso de drogas foi predominante na juventude, e a trajetória do uso de drogas confirmou uma escalada no uso de substâncias psicoativas, iniciando com o tabaco e/ou álcool e finalizando com o uso de crack.

Esses resultados sugerem a necessidade de uma reflexão profunda sobre as políticas de prevenção ao uso de tabaco/álcool, com a elaboração de programas preventivos mais eficientes, com enfoque na escola e no ambiente familiar. A fragilidade do acolhimento e da captura precoce de usuários na rede de atenção básica, a fim de evitar a trajetória progressiva do uso de drogas e a ausência de profissionais especializados na área, para atençáo direta ou matricial, são entraves para a prevenção e o tratamento dos usuários de drogas, e do crack em particular.

A identificação do consumo pode auxiliar os profissionais de saúde na prática clínica para o direcionamen- to do tratamento dos usuários de crack, com enfoque nas características do uso que dificultam ou facilitam a abstinência às drogas, ou ainda propor medidas de redução de danos que considerem o impacto do padrão de uso na efetividade e na adesão do tratamento.

Embora o estudo trabalhou com uma amostra de conveniência, náo permitindo a generalização dos dados a outros estudos, a presente série de casos mostrou potencialidade a partir de um numero reduzido de casos. A escolha por usuários com maior grau de ruptura social, realizada pela seleção dos usuários habituais ou dependentes de crack, favoreceu a identificação dos denominados "casos ricos em informação", de importância para o objeto em estudo.

Sugere a realização de estudos longitudinais para avaliar o desenvolvimento do consumo de substâncias e sua relação para o planejamento de intervenções em saúde. Por outro lado, verifica-se que seguimentos de longo prazo voltados ao registro dos desdobramentos do uso de crack ainda necessitam ser melhor explorados.

\section{REFERÊNCIAS}

1.Schenker M. O desafio da drogadicçấo na sociedade contemporânea. Cienc Saude Colet 2010;15(3):618-18.

http://dx.doi.org/10.1590/S1413-81232010000300001

2.Zilberman ML. Características clínicas da dependência de drogas em mulheres. 1998. (Tese). São Paulo. Faculdade de Medicina da Universidade de Sáo Paulo, 1998. 169p.

3.Seleghim MR, Marangoni SR, Marcon SS, Oliveira MLF. Vínculo familiar de usuários de crack atendidos em uma unidade de emergência psiquiátrica. Rev Latino-Am Enfermagem 2011;19(5): 1163-1170.

4.Dias AC, Araújo MR, Laranjeira R. Evolução do consumo de crack em coorte com histórico de tratamento. Rev Saude Publica 2011;45(5):938-948.

http://dx.doi.org/10.1590/S0034-89102011005000049

5.Raupp L, Adorno RCF. Circuitos de uso de crack na regiāo central da cidade de São Paulo (SP, Brasil). Cienc Saude Colet 2011;16(5):2613-2622.

http://dx.doi.org/10.1590/S1413-81232011000500031

6.Ribeiro L, Sanchez ZL, Nappo SA. Surviving crack: a qualitative study of the strategies and tactics developed by Brazilian users to deal with the risks associated with the drug. BMC Public Health 2010;10(671):1-10.

http://dx.doi.org/10.1186/1471-2458-10-671

7.Borini P, Guimarães RC, Borini SB. Usuários de drogas ilícitas internados em hospital psiquiátrico padrões de uso e aspectos demográficos e epidemiológicos. J Bras Psiquiatr 2003;52(3):171-179.

8.Sanchez ZM, Nappo SA. Sequência de drogas consumidas por usuários de crack e fatores interferentes. Rev saude publica 2002;36(4):420-430.

http://dx.doi.org/10.1590/S0034-89102002000400007 
9.Brasil. Agência Nacional de Vigilância Sanitária. Conselho Nacional de Saúde. Resolução no 29, 30 de junho de 2011. Diário Oficial [da] República Federativa do Brasil, Brasília, DF, 1 jul. 2011, Seçáo 1, p.62-63.

10.De Leon G. A comunidade terapêutica: teoria, modelo e método. São Paulo: Ediçóes Loyola, 2003, 496p.

11. Oliveira LG, Nappo SA. Caracterização da cultura de crack na cidade de São Paulo: padráo de uso controlado. Rev Saude Publica 2008;42(4);664-671. http://dx.doi.org/10.1590/S0034-89102008000400012

12.Bucher R. Prevenindo contra drogas e DST/Aids: populaçôes em situação de risco. Brasília, DF: CDIC, 1995, 28p.

13.Nugent R. Quiénes son los jóvenes. In: Ashford L, Clifton D, Kaneda T. La juventud mundial.Washington, D.C.: Population Reference Bureau, 2006, p.12.

14.Guimarães CF, Santos DVV, Freitas, RC, Araujo RB. Perfil do usuário de crack e fatores relacionados à criminalidade em unidade de internação para desintoxicação no Hospital Psiquiátrico São Pedro de Porto Alegre (RS). Rev psiquiatr Rio Gd. Sul. 2008;30(2):101-108.

http://dx.doi.org/10.1590/S0101-81082008000300005

15.IBGE divulga estudo especial da PME sobre cor ou raça (Endereço na internet). Rio de Janeiro: Comunicação Social (última atualização 11/2006; citado em 12/2011). Disponível em: http://www.ibge.gov.br/home/presidencia/noticias/noticia_visualiza.php?id_noticia $=737$

16.Midanik LT, Tam TW, Weisner C. Concurrent and simultaneous drug and alcohol use: results of the 2000 National Alcohol Survey. Drug Alcohol Dependence 2007;90(1):72-80.

http://dx.doi.org/10.1016/j.drugalcdep.2007.02.024

17.Gouzoulis-mayfrank E, Daumann J. The confounding problem pf polydrug use in recreacional ecstasy/MDMA users: a brief overview. J Psychopharmacol. 2006;20(2):188-93.

http://dx.doi.org/10.1177/0269881106059939

18.Santos R, Goecking CC, Goulart YN. Uso de tabaco entre adolescen- tes: revisão de literatura. SMAD, Rev. eletrônica saúde mental alcool drog 2010;6(2):350-364.

19.Brasil. Casa civil. Lei no 8.069, de13 de julho de 1990. Dispốe sobre o Estatuto da Criança e do Adolescente e dá outras providências. Disponível em: <http:// www.planalto.gov.br/ccivil_03/Leis/L8069.htm>. Acesso em: 19 set. 2011. 20.Oliveira MLF, Arnauts I. Intoxicação alcoólica em crianças e adolescentes: dados de um centro de assistência toxicológica. Esc Anna Nery 2011;15(1):83-89. http://dx.doi.org/10.1590/S1414-81452011000100012

21.Iglesias V, Cavada G, Silva C, Cáceres D. Consumo precoz de tabaco y alcohol como factores modificadores del riesgo de uso de marihuana. Rev Saude Publica 2007;41(4);517-522.

http://dx.doi.org/10.1590/S0034-89102007000400004

22.Labigalini JE, Rodrigues LR, Silveira DX. Therapeutic use of cannabis by crack addicts in brazil. J Psychoactive Drugs 1996;31(4):519-527.

23. Falck RS, Wang J, Carlson RG. Crack cocaine trajectories among users in a midwestern american city. Addiction 2007;102(9):1421-31.

http://dx.doi.org/10.1111/j.1360-0443.2007.01915.x

24.Brasil. Ministério da Saúde. Abordagens terapêuticas a usuários de cocaína/ crack no Sistema Único de Saúde. Brasília, DF, 2010. Disponível em: <http:// portal.saude.gov.br/portal/arquivos/pdf/abordagemsus.pdf $>$. Acesso em: 2 fev. 2011.

25.Brusamarello T, Maftum MA, Mazza VA, Silva AG, Silva TL, Oliveira VC. Papel da família e da escola na prevençáo do uso de drogas pelo adolescente estudante. Ciênc Cuid e Saúde 2010;9(4):766-773.

http://dx.doi.org/10.4025/cienccuidsaude.v9i4.13828

26.Vieira DL, Ribeiro M, Laranjeira R. Evidence of association between early alcohol use and risk of later problems. Rev Bras Psiquiatr 2007;29(3):222-227. http://dx.doi.org/10.1590/S1516-44462007000300006

27.Kessler F, Pechansky FHP. Uma visão psiquiátrica sobre o fenômeno do crack na atualidade. Rev psiquiatr Rio Gd. Sul. 2008;30(2):96-98.

http://dx.doi.org/10.1590/S0101-81082008000300003 